\title{
The effect of air pollution by nitrogen dioxide and meteorological parameters on a number of patients admitted to the Sestre milosrdnice University Hospital Centre Emergency Department
}

\author{
Hrvoje Pintarićc ${ }^{*}$, Sanja Pintarić ${ }^{2}$ Tomislava Bodrožić-Džakićc ${ }^{3}$ Robert Bernat ${ }^{4}$ \\ 'University Hospital Centre "Sestre milosrdnice", Zagreb, Croatia \\ ${ }^{2}$ First School of Economics, Zagreb, Croatia \\ ${ }^{3}$ Dubrava University Hospital Zagreb, Croatia \\ ${ }^{4}$ Magdalena Special Hospital for Cardiovascular Surgery and Cardiology, Krapinske Toplice, Croatia
}

Recent reviews indicate that ambient air pollution has important short and long-term effects on human health. Exposure to air pollutants ( $\mathrm{PM} 10, \mathrm{PM} 25, \mathrm{NO}_{2}, \mathrm{SO}_{2}, \mathrm{CO}, \mathrm{O}_{2}$ ) is in direct relation with higher morbidity and mortality of cardiovascular patients and with higher number of patients examined in the Emergency Department (ED). The aim of this study was to investigate correlation of certain meteorological parameters, concentrations of nitrogen dioxide $\left(\mathrm{NO}_{2}\right)$ in the air and the number of patients admitted to to the "Sestre milosrdnice" University Hospital Centre Emergency Department (ED), as well as the number of patients with cardiovascular referral diagnosis, according to the International Classification of Diseases (ICD-10), during the period of two years. Data on meteorological conditions and the concentrations of air pollutants were obtained from the State measuring stations Zagreb. There were 44,245 patients and 12,946 cardiovascular patients during the two years' period. The results showed that the total number of patients admitted to ED was higher during the summer, while the number of cardiac patients was higher in the winter. The highest concentrations of $\mathrm{NO}_{2}$ were measured during the winter and autumn, probably due to an increased use of motor vehicles. Results confirmed the hypothesis that high levels of $\mathrm{NO}_{2}$ lead to an increase in the number of cardiovascular patients admitted to the ED. Despite the fact that the highest concentrations of $\mathrm{NO}_{2}$ were recorded in the colder part of the year' the influence of the concentration of $\mathrm{NO}_{2}$ in the air on the number of admitted cardiovascular patients was statistically significant in the warmer part of the year when the slightest increase in the concentration of $\mathrm{NO}_{2}$ in the air lead a significant increases, the number of cardiac patients in the ED. These results indicate the need for further research of photochemical processes and their impact on cardiovascular patients.

KEYWORDS: air pollution, nitrogen dioxide concentration, meteorological conditions.

CITATION: Cardiol Croat. 2013;8(9):309-311.

Received: $31^{\text {st }}$ Jul 2013

*Address for correspondence: Klinički bolnički centar "Sestre milosrdnice", Vinogradska 29, HR-10000 Zagreb, Croatia.

Phone: +385-99-3787-147

E-mail: hrvojepintaric@yahoo.com

Table 1. Number of patients examined in Emergency Department in the period of June $30^{\text {th }} 2008$ to July $1^{\text {st }} 2010$ according to seasons (№ of patients examined in summer was corrected by $20 \%$ ).

\begin{tabular}{|l|c|c|}
\hline & Total № of patients & № of cardiac patients \\
\hline Total & $44245(100.0 \%)$ & $12946(100.0 \%)$ \\
\hline Spring & $11561(26.1 \%)$ & $3320(25.7 \%)$ \\
\hline Summer & $11689(26.4 \%)$ & $3055(23.6 \%)$ \\
\hline Autumn & $10503(23.8 \%)$ & $3226(24.9 \%)$ \\
\hline Winter & $10492(23.7 \%)$ & $3345(25.8 \%)$ \\
\hline
\end{tabular}


Table 2. Average values of meteorological characteristics according to seasons.

\begin{tabular}{|l|c|c|c|c|}
\hline & № of days & $\begin{array}{c}\text { Temperature } \\
\text { Median (range) }\end{array}$ & $\begin{array}{c}\text { Rel. Moisture } \\
\text { Median (range) }\end{array}$ & $\begin{array}{c}\text { Pressure } \\
\text { Median (range) }\end{array}$ \\
\hline Total & 730 & $13.4(-7.9-28.5)$ & $68.9(37.7-95.3)$ & $996(966-1020)$ \\
\hline Spring & 184 & $13.8(-1.2-26.5)$ & $60.7(37.7-91.4)$ & $997(966-1009)$ \\
\hline Summer & 184 & $22.5(13.3-28.5)$ & $61.5(41.0-89.5)$ & $996(984-1004)$ \\
\hline Autumn & 182 & $13.4(1.0-25.4)$ & $73.5(44.4-95.3)$ & $998(979-1013)$ \\
\hline Winter & 180 & $2.6(-7.9-14.5)$ & $78.9(43.6-94.0)$ & $994(971-1020)$ \\
\hline Kruskal-Wallis ANOVA & $\mathrm{p}=0.0000$ & $\mathrm{p}=0.0000$ & $\mathrm{p}=0.0000$ \\
\hline
\end{tabular}

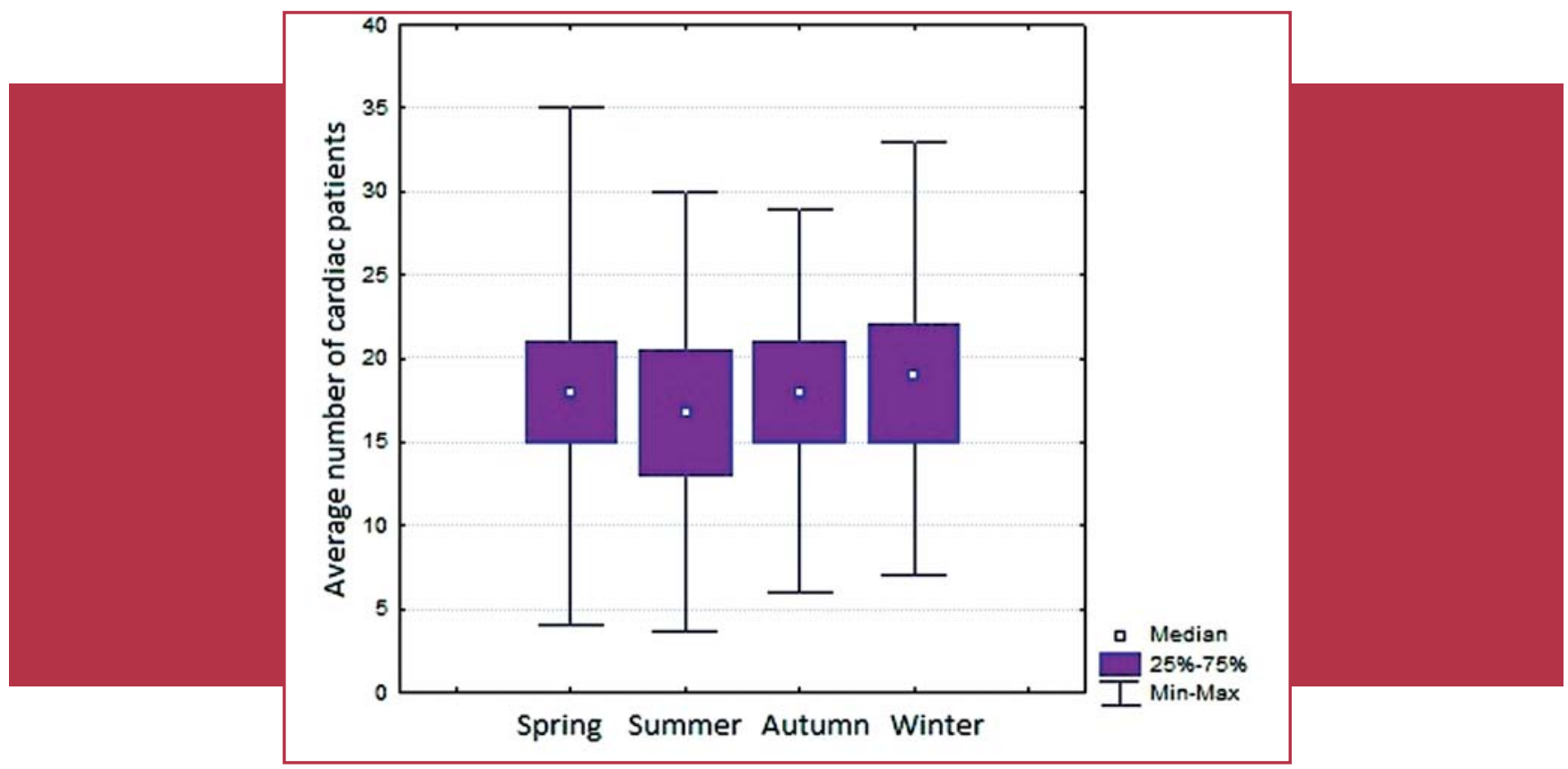

Figure 1. Number of patients with cardiac symptoms in Emergency Department according to seasons.

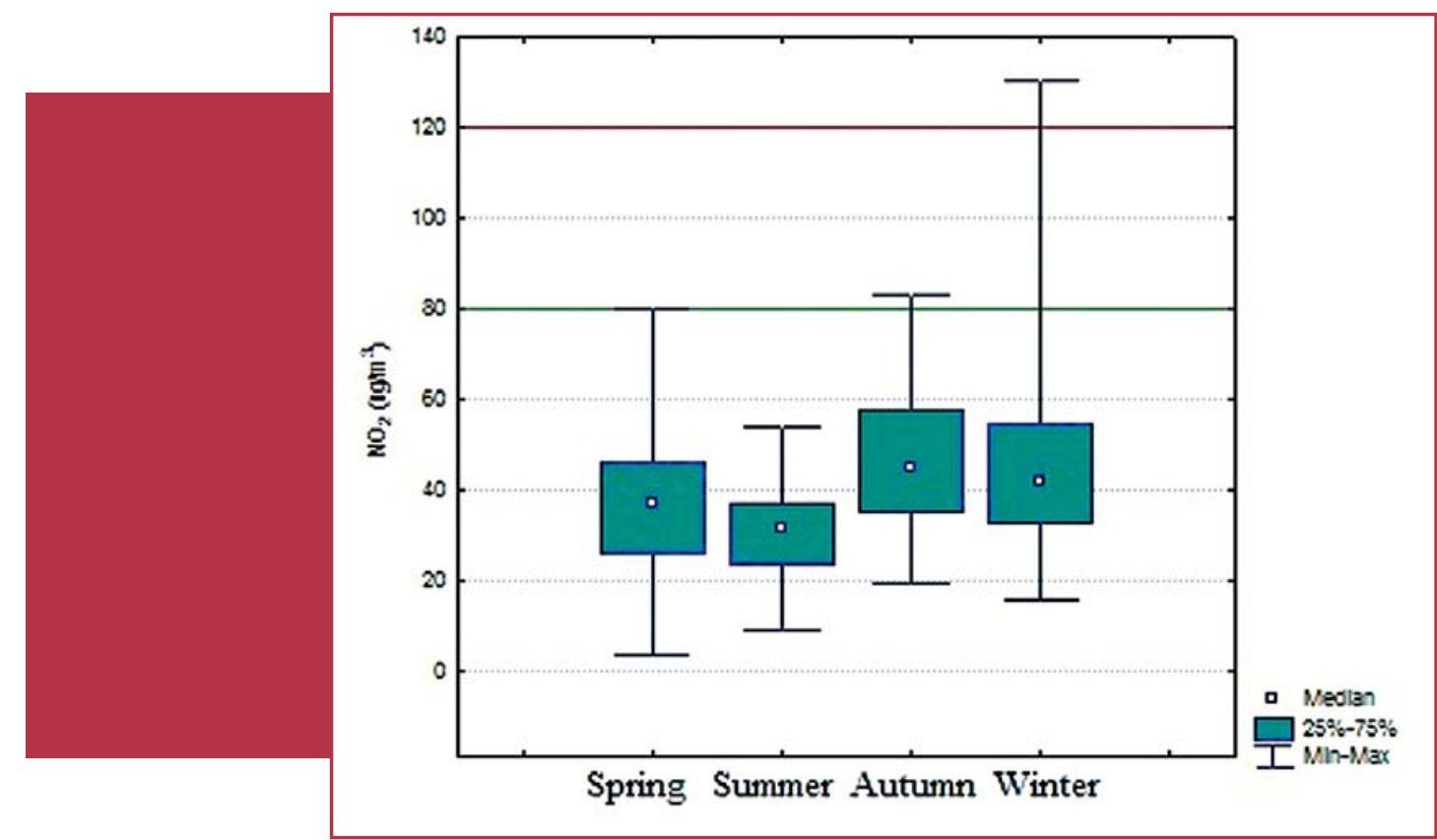

Figure 2. Average nitrogen dioxide concentrations according to seasons. 

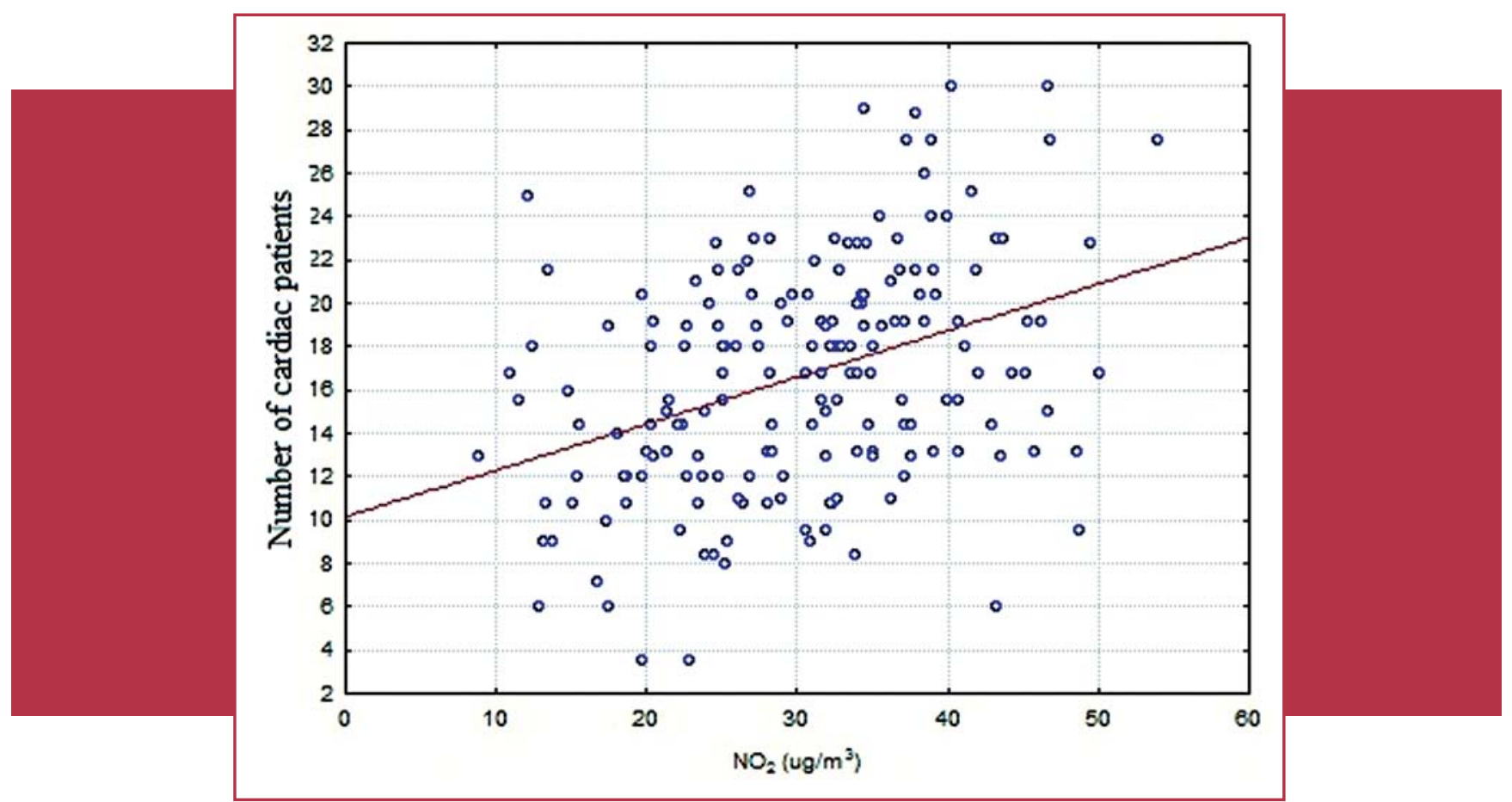

Figure 3. Correlation between number of patients with cardiac symptoms in Emergency Department and nitrogen dioxide in summer; Spearman's rang correlation $R=0.3763 ; p=0.0000$.

\section{Literature}

1. Hassing C, Twickler M, Brunekreef B, et al. Particulate air pollution, coronary heart disease and individual risk assessment: a general overview. Eur J Cardiovasc Prev Rehabil. 2009;16(1):10-5.

2. Hoek G, Brunekreef B, Fischer P, van Wijnen J. The association between air pollution and heart failure, arrhythmia, embolism, thrombosis, and other cardiovascular causes of death in a time series study. Epidemiology. 2001;12:355-7.

3. Chan CC, Chuang KJ, Su TC, Lin LY. Association between nitrogen dioxide and heart rate variability in a susceptible population. Eur J Cardiovasc Prev Rehabil. 2005;12(6):5806 . 